\section{Multiethnicity Is Divisive and Basically a Bankrupt Idea}

\author{
Stanley A. Rudin \\ Lima, $\mathrm{OH}$
}

The article by Phinney (September 1996) concerning ethnic groups commands thought. Having attained the age of 67 , with a certain irritable detachment that is due to semiinvalidism added to my view of things, I would like to point out some rather distasteful aspects of Phinney's views. Let me be clear: I am a White, male, heterosexual, European American Jew of Eastern European origins.

The whole idea of "multiethnicity" and its behavioral consequences is intellectually bankrupt and potentially fatal for this or any other society. As an undergraduate student who lived in a Jewish fraternity house at a medium-size Appalachian university, I can recall my friends being turned down by the medical school, with the added insult of being told over the phone, "The quota is filled up for the next five years for you Jewboys."

Although affirmative action ostensibly seeks to help the underdog, it has, in practice, ended up being a quota system, and everybody knows it.

The difficulty that Phinney (1996) had in trying to ascertain who belongs to what ethnic group merely illustrates the silliness of the whole idea. Skin color is determined by natural selection, in as few as two or three generations, by the amount of light that falls on any given population. The brighter the skies, the darker the skins of those who live there. Black people in Africa, Indians in India, Polynesians and Melanesians all tend toward dark skins. Northern Europeans and Eskimos tend toward light skin.

Body shape is also determined by climate. The colder the climate, the shorter and rounder the body; the warmer the climate, the taller and thinner the body. The idea here is to conserve heat radiation. Nilotic Blacks are generally very tall; Eskimos tend to be short and round.

From various sources (Cavalli-Sforza \& Cavalli-Sforza, 1995), it appears likely that one's physical and behavioral states are about $30 \%$ genetic in origin, about $30 \%$ cultural, and about $30 \%$ due to early experiences (from birth to about five years of age). And all of these factors are constantly changing because of the pressure of natural selection from the physical, social, cultural, and familial environments (Goleman, 1995; Healy, 1990; Herrnstein \& Murray, 1994;
LeDoux, 1996). Now, how in the world is one to do anything about this? Natural selection is going to take over anyway.

The notion of $e$ pluribus enum (i.e., from the many, one) is the motto of the United States, and I am quite pleased with it. When my grandparents came to the United States, the first thing that they did was apply for citizenship. Then they found a job and learned English, which was taught to them in a pressure-cooker atmosphere by embarrassed German European, American, White, Jewish people who were taken aback by all these repulsive immigrants.

Begone with the entire notion of ethnicity, says I. Emphasizing multiethnicity only accelerates the perception of differences and fragments us into little groups who are fighting each other. There are more important and survival-oriented matters to consider

\section{REFERENCES}

Cavalli-Sforza, L. L., \& Cavalli-Sforza, F (1995). The great human disporas. Reading, MA: Addison-Wesley.

Goleman, D. (1995). Emotional intelligence. New York: Bantam Books.

Healy, J. M. (1990), Endangered minds. New York: Simon \& Schuster.

Herrnstein, R. J., \& Murray, C. (1994). The bell curve: Intelligence and class structure in American life. New York: Free Press.

LeDoux, J. (1996). The emotional brain. New York: Simon \& Schuster.

Phinney, J. S. (1996). When we talk about American ethnic groups, what do we mean? American Psychologist, 51, 918-927.

Correspondence concerning this comment should be addressed to Stanley A. Rudin, 1252 Knollwood Drive, Lima, OH 45801

\section{Attitudes Toward Animal Research}

\author{
Roos Vonk \\ Leiden University
}

Eighty percent of the members of the American Psychological Association residing in the United States support the use of animals in psychological research (Plous, November 1996). Because I was not part of the population examined by Plous (I do not live in the United States), this comment is my response to all those American psychologists who favor animal research. I would like to point out what seem to me some obvious misconceptions that appear to be held even among the educated and, presumably, intelligent public surveyed by Plous.

First, some of the spontaneous comments given by Plous's (1996) respondents (see Table 5, p. 1173) reflect the common delusion that "might is right": Because we have the capacity to submit animals to our will, we feel there is nothing morally wrong by enacting this capacity (e.g., "We have a right to do whatever we decide we have a right to do"). Obviously, ability and morality are two independent issues. Surely we do not think it is right to experiment on mentally handicapped humans (even though they would make a far better subject sample than animals in most cases). We have the capacity to do so, but we can pride ourselves in the fact that we protect those who cannot protect themselves. Why would animals not be part of that less powerful group that requires our protection and respect?

A possible response to this question is provided by some other comments by Plous's (1996) respondents, suggesting that we should first be concerned with the humane treatment of other members of our own species before we engage in the "silly bourgeois cause" of animal rights (e.g." "Our priorities are screwed up when we worry more about treatment of animals ... [and] women's rights ... than we do about hurting people in a society falling apart!"; Plous, 1996, p. 1173). This argument reflects a second misconceptionnamely, that giving rights to animals would interfere with the resolution of problems among humans. Yet, acknowledging that animals have an intrinsic value (as the Dutch parliament recently did in a new animal welfare law) does not damage anybody's wellbeing. On the contrary, we have created many problems for our own species through our continuous disrespect for other species and for our natural environment: Not only have we polluted and destroyed our environment, but the meat industry in Europe and the United States (another example of animal abuse) contributes to the starvation of people in other parts of the world because cows and pigs are highly inefficient protein producers.

In actuality, concern for other people seems to go hand in hand with concern for oppressed groups and, hence, for animals as well. In agreement with Bowd and Shapiro (1993), I suggest that our abuse of animals may be the result of the very same mechanism that has produced discrimination against powerless groups within our own species, namely, our social categorization tendency that leads us (a) to favor our own group and derogate other groups and (b) to overestimate the differences between groups (e.g., Tajfel, 1982). If we look back now and think of the time when we abandoned slavery and child 
labor, it seems ridiculous to object that we should first have resolved the problems of White adults. Would we really say now that their interests were damaged and the resolution of their problems was obstructed because we gave rights to children and Blacks?

In our present state of cultural development, the idea that our treatment of animals is a form of discrimination similar to racism and sexism may seem unacceptable, but let us not forget that there have been times, not so long ago, when White men would have been similarly bewildered by the suggestion that their Black slaves should have equal rights. Many of them would have said, "Next they'll want us to give equal rights to apes!" (And yes, that is precisely what can be argued to be the logical next step [e.g., Cavalieri \& Singer, 1993].) The powerful majority is always going to insist that the problems of their group should be dealt with first. If this position had been accepted in the course of history, we would still not have given rights to women, Blacks, children, homosexuals, and so on. Similarly, if we now insist that problems of humans must be resolved first, the wait of other species might well be an indefinite one.

A final issue concerns the value of animal research for a better understanding of humans. In this respect, animals are useful to the extent that they resemble humans, psychologically or physiologically. In most animal research, the goal is to generalize the results to the human species. Both those who favor and those who oppose animal research can come up with examples of experiments whose results turned out to be either valid or invalid for humans. (As an aside, note that few respondents in Plous's [1996] sample actually used the results from animal research, and we do not even know whether their work was improved by this usage.) The point is, however, that the very assumption that animals are like humans makes it hard to legitimize why we do things to them that we would not do to humans. On the one hand, if we claim that they are entirely different, that they cannot feel and suffer like us, this means they are a useless subject sample in most studies. On the other hand, if they are similar enough to humans to be useful subjects, they may be able to suffer like humans, and there is no reason to deny them of the rights we have given to other powerless groups. Granted, they cannot verbally tell us that they suffer. But neither can a human baby nor a mentally retarded human, yet we are quite willing to accept that they can suffer like humans. We simply do not know whether animals suffer like humans. What we do know is that ani- mals, like humans, will do most anything to preserve their lives and freedom and to avoid pain.

Are we going to maintain that animals are so unlike humans that it does not harm animals if we lock them up without their consent? If so, it follows that the research most likely will not benefit us. Or are we willing to accept the possibility that animals, who are similar enough to humans to be suitable subjects, suffer in our laboratories? As the Americans say, you cannot have your cake and eat it too. So, which is it going to be?

\section{REFERENCES}

Bowd, A. D., \& Shapiro, K. J. (1993). The case against laboratory animal research in psychology. Journal of Social Issues, 49, 133-142.

Cavalieri, P., \& Singer, P. (1993). (Eds.). The Great Ape Project: Equality beyond humanity. New York: St. Martin's Press.

Plous, S. (1996). Attitudes toward the use of animals in psychological research and education. American Psychologist, 51, 1167 1180.

Tajfel, H. (1982). Social psychology of intergroup relations. Annual Review of Psychology, 33, 1-30.

Correspondence concerning this comment should be addressed to Roos Vonk, Department of Social Psychology, Leiden University, Wassenaarseweg 52, 2333 AK Leiden The Netherlands. Electronic mail may be sen via Internet to vonk@rulfsw.leidenuniv.nl.

\section{Respondent Knowledge Questioned}

\section{Yoke-Fong Lau and Carl Cheney Utah State University}

In "Attitudes Toward the Use of Animals in Psychological Research and Education: Results From a National Survey of Psychologists," Plous (November 1996) asked respondents about legal regulations governing animal research. (A companion article appeared in the November 1996 issue of Psy chological Science.) We believe some of the survey questions were inappropriately worded, the response options were too limited, and the questions required experience that we firmly believe few, if any, respondents possessed. Given that $90 \%$ of Plous's (1996a) respondents were in mental health services and clinical psychology, it is unlikely that they were experienced with animal research or any of the relevant regulations. Specifically, we don't believe many respondents who returned the survey had ever read the legal regulations pertaining to animal research, and therefore their responses were not based on knowledge but on something else.

To obtain some data about respondents' knowledge on this topic, we modified and shortened Plous's (1996a) survey and obtained responses from a group $(N=186)$ of undergraduate students at Utah State University. Plous's (1996b) results from psychology students "strikingly" resembled the findings from practicing psychologists (Plous, 1996a) probably because neither group had sufficient knowledge to answer meaningfully. That is, further training or experience of a nonrelevant nature did not alter the respondents' position. Because more than $75 \%$ of our respondents admitted knowing very little about any legal regulations governing animal research, we believe the exclusion of this response option in Plous's (1996a) survey (i.e., Questions 6, 7, and 11; see pp. 11791180 ) negates much of its impact. Although our results do not directly address what we see as problems with Plous's questions, we believe they do indicate that a fairly large sample of undergraduates are not in a position to make an informed response on this topic.

The understanding by the public with regard to how animal behavior studies are conducted and regulated at universities is a very important issue. We conclude from our results that respondents are generally uninformed about the use and care of laboratory animals and also about the laws and policies governing such animal use. Therefore, we recommend greater efforts be made toward educating students about actual animal experiments and about the existing laws and regulations.

\section{REFERENCES}

Plous, S. (1996a). Attitudes toward the use of animals in psychological research and education: Results from a national survey of psychologists. American Psychologist, 5I. 1167-1180.

Plous, S. (1996b). Attitudes toward the use of animals in psychological research and education: Results from a national survey of psychology majors. Psychological Science, 7, 352-358.

Correspondence concerning this comment should be addressed to Yoke-Fong Lau, Department of Psychology, Utah State University, Logan, UT 84322-2810. 


\section{The Separate World of Animal Research}

\author{
Kenneth J. Shapiro \\ Psychologists for the Ethical \\ Treatment of Animals
}

Homo sapiens are not always sapient, but they are inveterately curious. When Plous (November 1996) asked psychologists whether they supported or opposed animal research in psychology, he found that four out of five psychologists supported it. Why not? Scientists study everything; try to name something that they do not study. Scientists will always study other animals because animals are marvelous and varied beings.

The interesting and perplexing question fueling the current controversy is whether psychologists support animal research that involves pain or death. Even when the research was described as "institutionally approved and deemed of scientific merit," $62.1 \%$ and $44.4 \%$ of psychologists indicated that research involving pain or death to primates and rats, respectively, was unjustified (Plous, 1996).

If gratifying curiosity takes a backseat to the infliction of suffering, a further question is whether psychologists view the use of animals in psychological research as beneficial. Plous (1996) found that $92.2 \%$ of psychologists who were mental health workers indicated that they rarely, never, or only occasionally used findings from psychological research on animals.

Corroborating this result, in a study of 30 clinical psychologists specializing in the treatment of eating disorders, I found that 18 $(60 \%)$ indicated that they did not know that there were animal models of eating disorders (Shapiro, 1996, 1997). When these clinical psychologists were asked if they could name and describe an animal model of eating disorders, $20(67 \%)$ said they could not. Of the 10 (33\%) who said they could, most gave inadequate or vague descriptions. When they were asked to identify and describe the shamfeeding model of bulimia, 27 (87\%) could not. When they were asked their view of whether animal models of eating disorders influenced their treatment approach to these disorders, $27(87 \%)$ replied in the negative.

Finally, the clinicians were asked to indicate the journals that they found most helpful in their work. When the list of journals indicated as "most helpful for clinicians that specialize in or work with eating disorders" was compared with the list of journals in which the studies of nine investigators involved in research related to animal models of eating disorders were cited (in the Science Citation Index), there was no overlap. Clinicians specializing in the treatment of eating disorders generally are unaware of both the existence and the particular results of animalmodel research purporting to provide further understanding and effective treatment of these disorders.

Rowan (1993) used the metaphor of an "endless circle" to describe the relation between the clinic and the laboratory, whereas in a related context, Zurlo, Rudacille, and Goldberg (1994) referred to an "infinity circle." Taken together, my (Shapiro, 1996, 1997) and Plous's (1996) findings suggest that rather than representing a reciprocal interaction between animal research and applied psychology, a more fitting metaphor is separate worlds.

\section{REFERENCES}

Plous, S. (1996). Attitudes toward the use of animals in psychological research and education: Results from a national survey of psychologists. American Psychologist, 51, $1167-1180$.

Rowan, A. (1993). Analysis of the arguments against animal research. In A. Rowan \& J. Weer (Eds.), Summary and proceedings: The value and utility of animals in research (pp. 3-20). North Grafton, MA: Tufts Center for Animals and Public Policy.

Shapiro, K. (1996, October). Social scientific methods in the evaluation of animal model research. Poster session presented at the Second World Congress on Alternatives and Animal Use in the Life Sciences, Utrecht, The Netherlands.

Shapiro, K. (1997). Animal models of human psychology: Critique of science, ethics, and policy. Seattle, WA: Hogrefe \& Huber.

Zurlo, J., Rudacille, D., \& Goldberg, A. (1994). Animals and alternatives in testing: History, science, and ethics. New York: Mary Ann Liebert.

Correspondence concerning this comment should be addressed to Kenneth J. Shapiro, Psychologists for the Ethical Treatment of Animals, P.O. Box 1297, Washington Grove, MD 20880. Electronic mail may be sent via Internet to kshapiro@capacess.org.

\section{Animal Research in Psychology}

\section{S. Plous \\ Wesleyan University}

Each of the commentaries by Lau and Cheney (1997, this issue), Shapiro (1997, this issue), and Vonk (1997, this issue) contains interesting ideas and insights. I wish to take exception, however, with several of the methodological criticisms advanced by Lau and Cheney.

Lau and Cheney (1997) express three reservations about the surveys of American Psychological Association (APA) members and psychology majors reported in Plous (November 1996a, 1996b). First, they argue that Survey Items 6, 7, and 11 were "inappropriately worded" because these items did not include a don't know response option (such an option, known in survey research as a "DK filter," helps filter out respondents who are unfamiliar with a topic). Second, they claim that the survey required experience that most psychologists did not have, because $90 \%$ of the APA respondents were in "mental health services and clinical psychology" and therefore were unlikely to have had experience with animal research. Third, they contend that most of the students and professionals who participated in the study lacked sufficient knowledge of animal research to respond meaningfully to the survey.

Regarding the first issue, there is nothing about a filtered question that makes it more appropriate than an unfiltered question; each format has methodological advantages and disadvantages. In Schuman and Presser's (1996) authoritative book on question wording, they observed that an unfiltered format is generaily standard in survey research, and they found that adding a DK filter does not typically alter item marginals or item intercorrelations. Indeed, Lau and Cheney (1997) filtered one of my survey items in their modified version of the questionnaire, and although they did not report the results in their commentary, they obtained item marginals similar to those reported in Plous (1996b). (I thank Carl Cheney for sharing these results with me.) The bottom line here is that DK filters rarely lead to marginal shifts of more than 10\% (Ayidiya \& McClendon, 1990; Bishop, Oldendick, \& Tuchfarber, 1983), and there is no reason to suspect that they would have behaved differently in this case. The results of Lau and Cheney merely highlight the fact that most people have relatively little knowledge of animal regulations, a finding already noted in my articles (Plous, 1996a, p. 1175; Plous, 1996b, p. 356).

The second reservation expressed by Lau and Cheney (1997) is that $90 \%$ of respondents worked in mental health professions, and "few, if any, respondents" possessed experience with animal research. Of course, one need not participate in animal research to have an opinion about it, but leaving that objection aside, the correct figure is that $62 \%$ of respondents worked in mental health professions, as given in Table 1 of 
Table 1

Psychologists' Knowledge of the Animal Welfare Act

\begin{tabular}{|c|c|c|c|c|}
\hline \multirow[b]{2}{*}{ Knowledge measure } & \multicolumn{4}{|c|}{ Type of psychologist } \\
\hline & $\begin{array}{l}\text { All respondents answering } \\
\text { item } \mid n=3,102\}\end{array}$ & $\begin{array}{l}\text { Has conducted animal } \\
\text { research }(n=1,284)\end{array}$ & $\begin{array}{l}\text { Currently conducts animal } \\
\text { research }\{n=141\}\end{array}$ & $\begin{array}{l}\text { Member of APA Division } \\
6,25 \text {, or } 28(n=101)\end{array}$ \\
\hline \multicolumn{5}{|l|}{ Percentage who believe } \\
\hline Primates are covered & 97.0 & $98.1 * *$ & 98.6 & 99.0 \\
\hline Dogs are covered & 86.7 & 88.2 & $96.5^{* * *}$ & $97.0^{* *}$ \\
\hline Cats are covered & 84.8 & $86.5^{\star}$ & $95.7^{\star \star \star}$ & $97.0^{* \star *}$ \\
\hline Rats and mice are covered & 55.6 & 57.5 & 59.6 & 59.4 \\
\hline Pigeons are covered & 44.5 & $48.1^{* *}$ & 52.5 & $54.5^{*}$ \\
\hline Reptiles are covered & 16.6 & 17.4 & 17.7 & 14.9 \\
\hline Percentage gelling item correct & 28.8 & 27.7 & 31.2 & 32.7 \\
\hline
\end{tabular}

Note. The signilicance tests reported in the three right columns are chi-square tests for independence between a given type of psychologist and all other psychologists. APA $=$ American Psychological Association.

${ }^{*} p<.05$ by $\chi^{2}(1) .{ }^{* *} p<.01$ by $\chi^{2}(1) .{ }^{* *} p<.001$ by $\chi^{2}(1)$.

Plous (1996a, p. 1169). Of the respondents who were employed full-time, more than $30 \%$ $(n=1,026)$ worked in colleges, universities, or other academic settings, and when respondents were asked whether they had ever conducted animal research, $40 \%(n=1,570)$ answered affirmatively. Thus, contrary to the claim of Lau and Cheney, a substantial number of respondents had personal experience with animal research.

The last concern of Lau and Cheney (1997) is that most respondents had insufficient animal research training and knowledge to respond meaningfully to the survey, particularly with respect to questions about research regulations. This concern is based on two assumptions, both of which are testable to some degree: (a) Animal research training provides people with a superior knowledge of animal research regulations, and (b) knowledge of animal research regulations is, in turn, significantly related to attitudes toward animal research. To examine these assumptions, I analyzed respondents' answers to a six-part knowledge item in which they were asked to indicate whether certain animals are regulated under the Animal Welfare Act (the Animal Welfare Act is the main piece of federal legislation governing animal research).

As seen in Table 1, training in animal research did not translate into a superior knowledge of research regulations. For example, of the respondents who identified themselves as animal researchers or members of an animal research-related APA division, more than half incorrectly believed that rats and mice are covered under the Animal Welfare Act, and more than half incorrectly believed that pigeons are covered. Despite the extensive animal research experience and training these respondents undoubtedly had, fewer than one third got the complete six-part item correct (the correct answer is that primates, dogs, and cats are covered, but rats and mice, pigeons, and reptiles are not). These results suggest that survey filters based on a knowledge of research regulations would have excluded animal researchers at nearly the same rate as other respondents, even though animal researchers obviously have sufficient knowledge to meaningfully answer the survey.

Table 2 extends this analysis to the survey of undergraduate psychology majors, and the results here are much the same. Among students with animal research training (i.e., those who had taken a college course in which animals were used), $71 \%$ incorrectly believed that rats and mice are regulated under the Animal Welfare Act, and 57\% incorrectly believed that pigeons are regulated. These figures are significantly higher than the percentages obtained by students

\section{Table 2}

Psychology Majors' Knowledge of the Animal Welfare Act

$$
\text { Type of student }
$$

\begin{tabular}{|c|c|c|c|c|}
\hline Knowledge measure & $\begin{array}{l}\text { All respondents answering } \\
\text { item } n=1.103 \mid\end{array}$ & $\begin{array}{l}\text { Has taken an animal } \\
\text { course }(n=228)\end{array}$ & $\begin{array}{l}\text { Plans to attend groduate } \\
\text { school }(n=646 \mid\end{array}$ & $\begin{array}{l}\text { Would consider a coreer } \\
\text { conducting animal } \\
\text { research }(n=105 \mid\end{array}$ \\
\hline \multicolumn{5}{|l|}{ Percentage who believe } \\
\hline Primates are covered & 84.4 & 88.2 & $81.9 * *$ & 86.7 \\
\hline Dogs are covered & 74.8 & 78.1 & 74.8 & 72.4 \\
\hline Cats are covered & 72.3 & 76.8 & 72.6 & 71.4 \\
\hline Rats and mice are covered & 62.1 & $70.6^{* *}$ & 61.9 & 66.7 \\
\hline Pigeons are covered & 38.5 & $56.6^{\star \star \star}$ & 38.5 & 41.0 \\
\hline Reptiles are covered & 18.1 & 19.3 & 18.4 & 22.9 \\
\hline Percentage getting item correct & 18.9 & 16.7 & 18.7 & 15.2 \\
\hline
\end{tabular}

Note. The significance tests reported in the three right columns are chi-square tests for independence between a given type of student and all other students. ${ }^{* *} p<.01$ by $\chi^{2}(1) . \quad * * * p<.001$ by $\chi^{2}(1)$. 
who lacked animal research training. Even among students who planned to attend graduate school and who said they would consider a career conducting animal research $(n=$ 105 ), only $15 \%$ correctly answered the complete six-part question. In keeping with the results in Table 1, these findings cast doubt on the assumption that animal research training leads to a detailed knowledge of regulations (at least, as measured by this particular item on the Animal Welfare Act).

The other assumption made by Lau and Cheney (1997) is that respondents' knowledge of animal research regulations is an important determinant of their attitudes toward animal research. To test this assumption, I correlated scores on the six-part knowledge item (range: 0-6) with each of three standardized composite measures: overall support for animal research (Items 1, 3, and 4), overall support for animal research regulations (Items 6, 7, 8, and 12), and overall support for the use of animals in education (Items 13 and 14; for details on how the composite measures were constructed, see Plous, 1996a, pp. 1176-1177). The results showed very little relationship between knowledge and attitude measures. Among psychologists, knowledge of the Animal Welfare Act correlated .03 with support for animal research, -.07 with support for regu- lations, and - -.01 with support for the use of animals in education (among students, the correlations were $-.01, .05$, and - -07 , respectively). Moreover, even if there had been a strong relationship between knowledge and attitudes, it should be noted that most respondents overestimated the number of species covered under the Animal Welfare Act. Thus, if these respondents had known that rats, mice, pigeons, and reptiles are excluded under the Animal Welfare Act, any change in opinion would have been most likely in the direction of calling for increased regulation, not decreased regulation.

In sum, then, the methodological critique offered by Lau and Cheney (1997) is flawed on several grounds. At the same time, I certainly agree with their conclusion that psychologists should make every effort to educate students about animal research and the existing legal regulations.

\section{REFERENCES}

Ayidiya, S. A., \& McClendon, M. J. (1990). Response effects in mail surveys. Public Opinion Quarterly, 54, 229-247.

Bishop, G., Oldendick, R., \& Tuchfarber, A. (1983). Effects of filter questions in public opinion surveys. Public Opinion Quarterly, 47, 528-546.
Lau, Y.-F., \& Cheney, C. (1997). Respondent knowledge questioned. American Psychologist, 52, 1249.

Plous, S. (1996a). Attitudes toward the use of animals in psychological research and education: Results from a national survey of psychologists. American Psychologist, 51, 1167-1180.

Plous, S. (1996b). Attitudes toward the use of animals in psychological research and education: Results from a national survey of psychology majors. Psychological Science, 7, $352-358$

Schuman, H., \& Presser, S. (1996). Questions and answers in attitude surveys: Experiments on question form, wording, and context. London: Sage.

Shapiro, K. J. (1997). The separate world of animal research. American Psychologist, 52, 1250.

Vonk, R. (1997). Attitudes toward animal research. American Psychologist, 52, 12481249.

This material is based on work supported by the National Science Foundation under Grants SBR-9320062 and SBR-9616801.

Correspondence concerning this comment should be addressed to S. Plous, Department of Psychology, Wesleyan University, 207 High Street, Middletown, CT 06459. 0408. Electronic mail may be sent to splous@ wesleyan.edu. 